E3 Journal of Business Management and Economics Vol. 7(1). pp. 013-018 January, 2016

Available online http://www.e3journals.org

ISSN 2141-7482 (C) E3 Journals 2016

DOI : http://dx.doi.org/10.18685/EJBME(7)1 EJBME-15-020

Full Length Research Paper

\title{
The impact of perceived risk on willingness to buy in online markets
}

\author{
Oghenerume Freeman Orubu ${ }^{1}$ \\ ${ }^{1}$ Department of Business Administration, Delta State Polytechnic, Ozoro; Email: oruburume@gmail.com
}

Accepted 17 November, 2015

\begin{abstract}
The Internet today has become far from obscure as economic agents have come to accept the vast amount of information and possibilities that can be achieved using the internet. The usage of the internet as a shopping medium has raised issues about perceived risks, which has greatly influenced consumer attitudes towards shopping online. The main purpose of this study was to investigate the effect of perceived risks by consumers on willingness to buy products online, using six perceived risk parameters: time, performance, financial, psychological and social, and physical risks. Specifically, the greater the risk perceived by consumers to be associated with a product advertised online, the less the willingness to purchase it online. Comparatively, the psychological risk model performed best among the alternative specifications in terms of statistical significance of the coefficients of the indicators of perceived risk and correctness of their signs. The study concludes by exploring managerial implications arising from the research and recommends among others, that risk reduction strategies will go a long way in increasing consumer confidence in online market
\end{abstract}

Keywords: Internet, E-shopping, Perceived risk, Consumer behaviour.

\section{INTRODUCTION}

The Internet has grown from its first commercial use in the early1990s to being used by almost $27 \%$ of the world's population in just under 20 years (Howe, 2012). As the Internet continues to makes its reach into homes and businesses across the world, the opportunities for retailers will expand. Online shopping is a different process of shopping which unlike in-store shopping (Bitner 2001). It is the process which consumers go through to purchase products on the internet. The internet offers self-services to consumers and as such, it is available at consumer convenience, thus saving time and money, and reducing anxiety caused by service representatives (Liu and Zhou, 2011). It has become an electronic means or channel which is being used to conduct both businesses to consumer as well as business to business marketing (Seigel, 2003). Despite the emergence and possibilities that the internet offers in terms of online shopping, it is not without concerns. The usage of the internet for shopping has also raised issues about perceived risks, which has greatly influenced consumer attitudes towards shopping online.

With the growth of online shopping, where people can buy almost anything at anytime and from anywhere, consumers have to deal with risks they perceive about the product, the environment, or the buying process (Ko, Jung, Kim and Shim, 2004). For example, consumers may worry about purchasing products and services from "faceless" retailers, giving out personal and financial information online, buying products they can't examine physically before a purchase, loss of time and/or money, as well as what their friends and family will think about their purchases. These perceived risks occur when an individual recognizes the possibility of loss or some other negative consequence from using or purchasing a product or service (Bauer, 1960). These perceived risks may increase when consumers consider shopping from internationally-based retailers that cross global and cultural boundaries. As such there has been amplified interest by retailers and academicians alike in how people from around the world might perceive the risks affecting how, when, and if consumers will purchase a product or service online.

Internet retailers need to understand online consumer purchasing behavior in order to design and support effective retail Web sites that match the preferences of their target market (Vijayasarathy and Jones, 2000). Due to 
an increase in the pace of globalisation for world economies, there has been an increase in the competitive nature of firms, and many companies are seen taking to forms of unconventional marketing, and this has been almost in full done by the use of the internet. As more businesses are coming to adopt the internet as means of reaching consumers efficiently, and also conducting marketing activities, there exists elements of risks, and this puts consumers as well as the credibility of the marketing firm at risks.

This research provides a comprehensive picture of perceived risk in online shopping, focus on antecedents of purchasing intentions in online shopping, and study the direct effects of risk variables on purchase intentions so as to reveal the importance of each variable used. Theoretically, this research study aims to further provide evidence to buttress the multi- dimensional perceived risk theory and the technology acceptance model. By conducting this research, it is hoped the outcome will demonstrate the influence perceived risk has on willingness of consumers to buy online and at a practical level, assist marketers and online retailing developers in designing more efficient risk reducing strategies for online retailers.

\section{LITERATURE REVIEW}

With the introduction of residential Internet in the early 1990s, consumer buying behavior regarding online shopping, including perception of risk has become an important area of research. Although research has shown that consumers perceive benefits of using the Internet (Salisbury, Pearson, Pearson, and Miller, 2001; O'Cass and Fenech, 2003; Park, Lee, and Ahn, 2004: Shih, 2004), negative effects from the perception of risk have also been found to have a negative impact on shoppers' attitudes towards online shopping (O'Cass, 2001; Shih, 2004; Heijen, Verhagenm and Creemers, 2003) as well as a negative effect on a person's intention to shop online (Korgaonkar and Wolin, 1999; and Salisbury, Person, and Miller, 2001). Jarvenpaa and Todd (1997) examined the influence of perceived risk from a multidimensional perspective. Findings of the study suggest the influence of economic, social, performance, physical, and privacy risks on attitudes toward online shopping and that consumers perceive increased risk when shopping in this format (Jarvenpaa and Todd, 1997; Featherman and Pavlou, 2003).

\section{Online shopping risk dimensions}

Consumers are more cautious when shopping or considering shopping online (Lim, 2003). Previous literatures have suggested that perceived risk is a crucial factor in determining the rate of acceptance of online shopping. Forsythe and Shi (2003); Lim (2003); Cases (2002) noted that the internet unlike other purchasing channels causes a larger amount of uncertainty for individuals. This may be due to the complexity, ease of use or accessibility (Almousa, 2011). Due to the uncertainty involved in internet purchases, the internet has been considered a more risky option as opposed to in-store shopping (Bhatnagar and Ghose, 2004; Kim and Prabhaka, 2002). Empirical studies (Forsythe and Shi 2003; Bhatnagar and Ghose, 2004) have attempted to show users of internet being aware of internet shopping, but evidence have indicated users still hesitating to purchase online. In the online context, some risks are seen as having effects more than others. Bhatnager and Ghose, (2004); Cases (2002); Forsythe and Shi, (2003) noted that privacy, security and financial concerns are issues that adversely hinder online shopping.

Financial/Security risk: Online financial loss concerns the potential expense of returning a product, the likelihood of additional hidden cost such as shipping, difficulty in getting money back, and the lack of protection of credit-card information (Hassan et al., 2006). Cases (2002), distinguishes between payment risk and financial risk by means of the risk source, internet, and remote transaction respectively. Payment risk concerns the financial consequences engendered by giving one's credit-card number on the internet (Martin and Camarero, 2009), whereas financial risk refers to money lost in the case of shipping, bad purchase or exchange.

Performance risk: Product performance risk may also result from a poor product choice because of the shopper's inability to accurately judge the quality of the product online. The ability to judge the product or service quality online may be limited by barriers to touching, feeling, and trying the product or service, inaccurate product colours, and insufficient information on quality attributes relevant to the consumer resulting in increased product performance risk (Forsythe and Shi, 2003).

Physical risk: In online context, refers to chances of any physical injury caused by online shopping (Hassan et al., 2006; Casalo et al, 2007, Mitchell, 1999; Kim et al, 2007). This could involve possible eyestrain from overuse of the computer.

Psychological Risk: If the extent of negative impact on consumers self image arises as a result of product usage, it may be referred to as psychological risk (Crespo et al, 2009; Jacoby and Kaplan, 1972). Schiffman and Kanuk (2004) describes psychological risk as the possibility of a substandard product having a negative 
impact on a consumers ego, thus, psychological risk relates to an individual's personal assessment of disappointment. In an online context, it reflects concern about the psychological discomfort and tension that may arise because of online shopping (Hassan et al., 2006). It refers to consumer possibly feeling a sense of anxiety or unwanted tension from shopping online.

Social Risk: In online context, refers to the likelihood that online shopping will affect the way others think of the online prospective shopper (Hassan et al, 2006; Lin and Sun, 2009; Chan and Cheng, 2008). It is the concern that those whose opinion the online shopper values will think of the online prospective shopper as being foolish or showy. Cases (2002) states that the source of social risk is the internet, and it is therefore the fear of the reaction of friends and family concerning the use of the internet as a mode of purchase.

Time Risk: This risk includes the time and effort lost in returning or exchanging the product, technological problems such as a slow website server, delivery time, and waiting time (Almousa, 2011). Furthermore, when purchasing on the internet, the consumer does not pay for the product and receive the product immediately, but he/she has to wait for delivery of the already paid-for product, and this delivery could take too long, thus wasting the time where the consumer could already have been using the product.

\section{METHODS}

This study investigates the perceived risks in online shopping that influences consumer willingness to buy clothing online consumer decision making as regards online shopping. This research describes the characteristics of respondents in relation to consumer shopping online, thus, the degree of use of online shopping by different consumers will be of importance.

\section{Sample plan and description}

In selecting the sample, a non-probability sampling technique was used; the selection depended wholly on the researcher's idea, by choosing randomly from the sample population. The participant demography was chosen to cover ages from 18 to 60 which is an active segment of the population, seen by Liu and Wei (2003) as a segment actively involved in online shopping. Collecting the data for this study is conducted using personal surveys. A sample size of 210 was chosen for this research. It involved personal interviews, and participants were approached at home and on streets. It was aimed at internet users in Glasgow, United Kingdom.

\section{Instrument development}

Self-administered street-intercept questionnaire was developed. This was constructed to include measures of consumer experience, risk perception, purchasing intentions, as well as consumer demographics. A multi item measurement scale was developed for the variables; it was constructed to effectively measure the various components of perceived risks in online clothing. Development of the questionnaire, involved four segments. The first segment intended to capture the user characteristics or internet usage, which included the number of hours that was spent online and if the respondent has shopped online. The intention for adding this segment is to effectively capture the characteristics of respondents, and possibly, know where their perceptions of perceived risk in online shopping tend to. The second segment involved the perceived risk components, as well as willingness to buy constructs. Questions in this section was measured on a five point likert Scale of (strongly disagree, somewhat disagree, neither, somewhat agree, and strongly agree) the questions for this segment was generated from various literatures in the field of perceived risks, (Featherman and Pavlou 2003; Li and Zhang, 2002; Crespo et al, 2009; Siegrist et al, 2008; Jarvenpaa and Todd 1997; Jacoby and Kaplan, 1972; Mitchell 1999). In this segment, the risk components included performance risks, financial risks, privacy risks, psychological risks, and time risks. A section was dedicated to measure willingness to buy as well as usage of the internet. Constructs in this segment was measured on a five point likert scale (strongly disagree, somewhat disagree, neither, somewhat agree, and strongly agree). In measuring willingness to buy, 7 statements were given and respondents were to agree with these statements, based on a 5 point likert scale. The questionnaire used closed ended questions to enable coding of response easy. Questionnaires were used in this study as opposed to other tools of measurement due to ease of construction and it is easily understandable by the respondents.

\section{ANALYSIS}

From the data collected, more females (139) shop online than males (59). Also, the number of males that do not have previous online shopping experience exceeds that of females at ratio $2: 1$ respectively (see table 1 )

The time spent online by the respondents, showed an increase in chances of shopping online (Table 2). All unemployed respondents have had online shopping experience (Table 3 ). 73 out of 85 part time respondents had previous online shopping experience. 
Table 1. Gender and online shopping

\begin{tabular}{rcccc}
\hline Gender & Male & Female & Total \\
\hline Shopped online: & No & 14 & 7 & 21 \\
& Yes & 59 & 130 & 189 \\
\hline Total & $\mathbf{1 3 7}$ & $\mathbf{1 3 7}$ & $\mathbf{2 1 0}$ \\
\hline
\end{tabular}

Table 2. Time spent online and shopping online

\begin{tabular}{lcccccc}
\hline Hours spent online & & $<$ hhours & $\mathbf{5 - 1 0}$ hours & $\mathbf{1 0 - 2 0}$ hours & $\mathbf{> 2 0}$ hours & Total \\
\hline Shopped Online: & No & 9 & 2 & 2 & 8 & 21 \\
& Yes & 21 & 30 & 15 & 123 & 189 \\
\hline & Total & $\mathbf{3 0}$ & $\mathbf{3 2}$ & $\mathbf{1 7}$ & $\mathbf{1 3 1}$ & $\mathbf{2 1 0}$ \\
\hline
\end{tabular}

Table 3. Job Status and shopping online.

\begin{tabular}{cccccccc}
\hline Job Status & Fulltime & retired & Part-time & student & unemployed & total \\
\hline Shopped online: & No & 4 & 3 & 12 & 2 & 0 & 21 \\
& Yes & 44 & 40 & 73 & 21 & 11 & 189 \\
\hline Total & $\mathbf{4 8}$ & $\mathbf{4 3}$ & $\mathbf{8 5}$ & $\mathbf{2 3}$ & $\mathbf{1 1}$ & $\mathbf{2 1 0}$ \\
\hline
\end{tabular}

For full time and retired employees, there was a close margin at 44 and 40 respectively with online shopping experience.

Taking into account the sample characteristics, it gives an indication of which user group, working class, or gender groups can be targeted for strategic marketing purposes, thus making development of marketing strategies easy for online marketers.

The general model specifies if there exists any relationship between willingness to buy (the dependent variable) and the different dimensions of perceived risk (the independent variables).

Risk dimensions were subjected to reliability checks. According to Zikmund et al. (2003), reliability tests measures the degree to which the items are free from error. This is important in ascertaining how consistent the result for this study is. In this research, the cronbach alpha values were calculated in other to assess the reliability of the multiple scale items. The reliability coefficient as a rule of thumb takes values between $0.8>$ $\alpha \leq 0.7$ as acceptable and as noticed, our value (0.727) falls between this range. Of all the risk dimensions, only psychological, time, and social risks tested positive in predicting consumer shopping attitudes online as they showed significance level lower than 0.05. (Table 4). this can be adduced to the economic structure of the case study area where a large proportion of the populace are educated, as well as having vast knowledge of the benefits of online shopping. Previous studies (Zheng et al., 2012; Brosadahl and Almousa, 2010) have shown varying results in different economies.

The results of this study have been able to establish existence of relationship between time, performance, financial, psychological, privacy risks and willingness to buy online. If these risks are high, the tendency of consumers willing to accept the internet as an alternative method of shopping will definitely be low. In the case of privacy risks, users will fear receiving unwanted emails as it will result to spam. More recently, there have been issues of online marketing trackers (cookies) which can track how users access sites and collect information which are then used to send product suggestions and offers. This has been a controversial method, and as such users may want to reduce online purchasing to avoid this. Also in terms of financial risk, internet users have feared giving out credit card details to unfamiliar vendors or marketer. This risk in this study, did not significantly affect consumers' willingness to buy online. For time risk, users may feel uneasy with the product search time, the loading time, and the delivery time 
Table 4. Coefficients table for various risk dimensions

\begin{tabular}{lccccccccc}
\hline Variable & R & Std Err & Adj R & Sig & F & R2 & SD & Mean & DW \\
\hline Financial & 0.13 & 0.84 & 0.003 & 0.30 & 1.20 & 0.17 & 0.11 & 4.10 & 1.56 \\
Performance & 0.14 & 0.83 & 0.008 & 0.20 & 1.51 & 0.02 & 0.12 & 4.11 & 1.56 \\
Physical & 0.06 & 0.84 & -0.006 & 0.68 & 0.37 & 0.00 & 0.05 & 4.11 & 1.54 \\
Psychological & 0.48 & 0.74 & 0.22 & 0.00 & 15.9 & 0.23 & 0.41 & 4.10 & 1.67 \\
Time & 0.35 & 0.79 & 0.102 & 0.00 & 5.76 & 0.12 & 0.29 & 4.10 & 1.71 \\
Social & 0.34 & 0.79 & 0.105 & 0.00 & 7.09 & 0.12 & 0.29 & 4.11 & 1.57 \\
\hline
\end{tabular}

associated with the product being purchased. This can affect a consumers' willingness to continue with the shopping process. Moore (2008) did a research on abandoned cart syndrome in online shopping, and it was found out that page loading time as well as delivery time accounted for less zeal in consumers using the internet as an alternative mode of shopping as opposed to instore shopping. Psychological risk is also seen to affect willingness to buy products online. Access to internet and time spent. On the internet are factors that are seen to foster this type of risk (Kim and Kim, 2009). Performance risk in this study is seen not to have significant effect on willingness to buy. This can be attributed to the type of product being purchased online (Bertea, 2010).Consumers will feel more concerns about the performance of a product if it comes as a high value product.

This implies that consumers in this study are always anxious about purchasing decisions, and this can adversely influence the willingness to buy. Results show a direct relationship between willingness to buy and time, psychological and social risk this in agreement with previous researches of Chan and Cheng, 2008; kim and kim, 2009; Park, et al, (2004). Also in this study, differences are found to exist between the different risk components; where consumers perceive more performance and privacy risks in shopping for products online. In general, it can be said that willingness to buy is affected in varying degrees by the various risk dimensions used in this study.

Another implication of this finding is that online marketers must devise ways of attracting potential consumers by placing emphasis on security measures, which can reduce the anxiety of consumers. Marketers can also make online shopping more attractive to prospective shoppers by consistently informing consumers about benefits that accrue from online shopping such as access to a wide range of goods which are offered at competitive prices, and are purchased usually at the convenience of the buyer. As a risk reduction strategy, marketers could offer money back guarantees to shoppers, or creating a review/testimony column on the website, to enable users comment on the merits and demerits of products.

However, online marketing strategies are not enough to reduce the risks in online shopping. Other studies have shown that as consumers cannot physically assess goods prior to purchasing; it becomes difficult to evaluate the benefit derived from consuming a product before purchase (Mitchell, 1999; Gabarino et al., 2004).

This research has managerial implications in the sense that it presents online marketers the varying effects of consumers risk perceptions in shopping online. Management can then adopt risk reducing strategies to attract potential buyers. In reaction to the findings in this research, strategies should be created by online marketers that will help online marketers to create strategies that will help reinforce product information, at the same time, help consumers cope with the uncertainties that may arise from purchases. Providing product information could help encourage online shopping. This could go to the extent of the online marketer trying to provide comprehensive product information such as three dimensional virtual modelling, content, finishes, product consumer rating, as well as instructions could act as enablers to reduce performance risk associated with purchasing of products on the internet.

\section{Conclusion}

Understanding usage of the internet by consumers as a different shopping avenue, from the traditional in-store method, has been of paramount importance to online marketing researchers. This research has shown that online shopping is still considered as risky to some extent. The findings have shown that the greater the risk associated with online shopping, as perceived by consumes, the less the willingness to buy online. In a bid to increase sales volumes, online marketers must place emphasis on efficient and trusted shipping service providers so as to reduce perceived time risk and avoid non-delivery or delay of products. 


\section{REFERENCES}

Almousa M (2011), Perceived Risk in Apparel Online Shopping: A Multi Dimensional Perspective, Canadian Soc. Sci. 7(2): 23-31

Bauer R (1967). Consumer behaviour as risk taking. In Cox, D. F. (ed.): Risk Taking and Information Handling in Consumer Behaviour. Boston University Press, Boston, pp. 23-33

Bettman JR (1973). Perceived risk and its components: A model and empirical test, J. Marketing. Res. 10(2): 184-190.

Bhatnagar A, Ghose S (2002). Segmenting consumers based on the benefits and risks of Internet shopping. J. Bus. Res. 57: 1352-1360.

Bitner MJ (2001). Self-service technologies: What do customers expect? Marketing Manage. 10(1): 10-11.

Cases A-S. (2002). Perceived risk and risk-reduction strategies in Internet shopping. The International Review of Retail, Distribution. Consum. Res. 12(4): 375-394

Chang H, Chen S (2008), "The impact of online store environment cues on purchase intention: Trust and perceived risk as a mediator", Online. Info. Rev. 32(6): $818-841$.

Claudia I (2012), "Perceived Risk when Buying online", Econ. Series. 22(2): 63-73.

Featherman MS, Pavlou PA. (2003). Predicting e-services adoption: a perceived risk facets perspective. Intl. J. Human-Computer. Studies. 59: 451-474.

Fenech T, O'Cass A (2001). Internet users' adoption of Web retailing: User and product dimensions. J. Product. Brand Manage. 10(6): 361-81.

Forsythe SM, Shi B (2003). Consumer patronage and risk perceptions in internet shopping. J. Bus. Res. 56(1): 867-75.

Jacoby J, Kaplan LB (1972). The components of perceived risk. Advances in Consumer Research, 1(1): 328-393.

Jarvenpaa SL, Todd PA (1997). Is there a future for retailing on the internet. In Electronic marketing and the consumer. R.A. Peterson, 139-54. Thousand Oaks, CA: Sage Publications.

Lim N (2003) Consumers" perceived risk: sources versus consequences" Electron. Commerce Res. Applications: 216-228.

Liu X, Wei KK (2003). An empirical study of product differences in consumers' e commerce adoption behavior. Electron. Commerce Res. Applications. 2(3): 229-239.

Martin S, Camarero C (2009). "How perceived risk affects online buying" Online. Info. Rev. 33(4): 629-654.

Masoud EY (2013). "The Effect of Perceived Risk on Online Shopping in Jordan" Eur. J. Bus. Manage. 5(6): 113-210

Mitchell VW (1999). Consumer perceived risk: Conceptualizations and models, Eur. J. Marketing. 33(1): 164-196.

O'Cass A, Fenech T (2003). "Web retailing adoption: Exploring the nature of internet users web retailing behaviour" J. Retailing. Consum. Services. 10(2): 81-94.

Pavlou PA, Fygenson M (2006). Understanding and predicting electronic commerce adoption: An extension of the theory of planned behavior. MIS Quarterly 30(1): 115 - 143.

Pires G, Stanton J, Eckford A (2006). " Influence on the perceived risk of purchasing online. J. Consum. Behav. 4(2): 118-131.

Rowely J (2000). Product search in e-shopping: A review and research propositions. J. Consum. Marketing. 17(1): 20-35.
Salisbury WD, Pearson RA, Pearson AW, Miller DW (2001). Perceived security and World Wide Web purchase intentions. Industrial Manage. Data. Systems. 101(4): 165 - 177.

Shih HP (2004). An empirical study on predicting user acceptance of eshopping on the web. Info. Manage. 41(3): 351-368.

Siegel C (2003). Internet Marketing: First Edition, United States, Houighton Mifflin Inc.

Vijayasarathy LR, Jones JM (2000). Print and Internet catalog shopping: Assessing attitudes and intentions. Internet Research: Electronic. Networking Applications and Policy 10(3). 191-202.

Wood CM, Scheer LK (1996). Incorporating perceived risk into models of consumer deal assessment and purchase intent. Advances. Consum. Res. 23(3): 399-406. 